\title{
Representações sociais da reforma do Judiciário - um estudo baseado nas perspectivas dos servidores do Tribunal de Justiça do Estado da Bahia
}

\author{
Fernanda Filgueiras Sauerbronn
}

Universidade Federal do Rio de Janeiro (UFRJ) / Faculdade de Administração e Ciências Contábeis

Rio de Janeiro / RJ - Brasil

João Felipe Rammelt Sauerbronn

Universidade do Grande Rio (Unigranrio) / Programa de Pós-Graduação em Administração

Rio de Janeiro / RJ - Brasil

\begin{abstract}
A presente pesquisa investiga como os servidores de um tribunal de justiça entendem a reforma do Judiciário. A teoria das representações sociais é utilizada como referencial teórico e abordagem metodológica, operacionalizada por meio de análise de conteúdo. A partir das palavras evocadas e dos textos coletados, emergiram quatro dimensões — reforma gerencial, ampliação da cidadania, aspectos legais e reflexões sobre o Judiciário - 10 categorias e 31 subcategorias. Ao fim são traçadas considerações acerca da relevância da percepção dos servidores quanto a futuros desenvolvimentos de estratégias organizacionais e políticas públicas orientadas para a reforma dos tribunais de justiça.
\end{abstract}

Palavras-chave: Poder Judiciário; reforma do Judiciário; reforma do Estado brasileiro; teoria das representações sociais.

Representaciones sociales de la reforma judicial - un estudio basado en las perspectivas de los servidores del Tribunal de Justicia del Estado de Bahía

Esta investigación indaga cómo los servidores de un tribunal de justicia entienden la reforma judicial. Los autores utilizan la teoría de las representaciones sociales como una aproximación teórica y metodológica, implementada con el apoyo del análisis de contenido. Del análisis de las palabras y textos evocados emergieron cuatro dimensiones para la reforma — reforma de la gestión, expansión de la ciudadanía, aspectos legales y reflexiones sobre el Poder Judicial —, 10 categorías y 31 subcategorías. Al final, se hacen consideraciones sobre la relevancia de la percepción de los servidores que pueden contribuir a un mayor desarrollo de las estrategias organizativas y políticas públicas para reformar los tribunales.

Palabras clave: Poder Judicial; reforma judicial; la reforma del Estado brasileño; la teoría de las representaciones sociales.

DOI: http://dx.doi.org/10.1590/0034-7612130108

(c)) BY-NC

Artigo recebido em 4 fev. 2014 e aceito em 17 dez. 2014. 


\begin{abstract}
Social representations of the judicial reform - a study based on the perspectives of the employees of the Court of Justice of Bahia state

This paper investigates how the public employees in a court of law understand the judicial reform. The Social Representations Theory is used as a theoretical reference and methodological approach, operated through content analysis. Based on the words and texts collected, the authors analyze the reform in four dimensions - management reform, expansion of citizenship, legal aspects and reflections on the Judiciary - and 10 categories and 31 subcategories had emerged. At the end, the authors present some considerations about the relevance of the employees' perception over the future development of organizational strategies and public policies oriented to reform the justice courts.
\end{abstract}

KEYW ORDs: Judicial Power; judicial reform; reform of the Brazilian State; social representations' theory.

\title{
1. Introdução
}

O processo de transformação da administração pública brasileira de burocrática para gerencial, que teve início na segunda metade da década de 1990, alcançou o Poder Judiciário com algum atraso. A resistência de magistrados e juristas foi superada pela pressão de diversos setores da sociedade e em 30 de dezembro de 2004 foi publicada a Emenda Constitucional no 45, que serve como marco para o início da reforma do Poder Judiciário. Como aponta Sadek (2004), as reformas eram inevitáveis, assim como a alteração da identidade e do perfil da instituição que sempre teve na tradição uma garantia segura contra as inovações.

O Judiciário é um poder de Estado e, simultaneamente, uma organização prestadora de serviços que possui atribuições de serviço público encarregado da prestação jurisdicional (Sadek, 2004). No entanto, a prestação de serviços nunca foi preocupação do poder e a área meio sempre foi considerada uma área menos importante por magistrados e juristas. A reforma do Judiciário, contudo, trouxe o aumento da importância da área meio a partir da criação do Conselho Nacional de Justiça (CNJ). O CNJ é o órgão gestor do Poder Judiciário e cuida das ações que visam ao aperfeiçoamento do serviço público de prestação jurisdicional, com especial foco no controle e na transparência administrativa e processual (Sauerbronn e Lodi, 2012).

Do ponto de vista do campo da administração pública, poucas pesquisas têm se preocupado com aspectos da administração do Judiciário. Em que pesem as variadas contribuições recentes de Sauerbronn (2011), Nogueira e colaboradores (2012), Sauerbronn e Lodi (2012), Sena, Silva e Luquini (2012) e Gomes e Guimarães (2013); ainda assim, como aponta Nogueira (2010), ainda são poucos os trabalhos sobre o Judiciário desenvolvidos por pesquisadores do campo. Em alguma medida, o reduzido número de pesquisas sobre a gestão do Judiciário pode ser justificado em função da já mencionada pouca importância da área meio para o poder e da distância entre os operadores do sistema judiciário e a academia da administração pública.

Nesse sentido, o presente trabalho busca contribuir para a aproximação dos problemas da gestão do Judiciário ao campo da administração pública a partir de uma investigação a 
respeito da forma com a qual servidores de um tribunal de justiça entendem a reforma do Judiciário. Essa proposta parte da utilização da teoria das representações sociais (TRS) como referencial teórico e instrumento para a compreensão da reforma do Judiciário, na identificação dos conhecimentos e das práticas sociais que se articulam no espaço relacional dos servidores.

Trata-se, portanto, de uma pesquisa de caráter eminentemente exploratório, baseada em uma abordagem qualitativa que permite o acesso ao universo de significados dos servidores. Foram coletados dados junto a 263 servidores do Tribunal de Justiça do Estado da Bahia que responderam a um instrumento de coleta de dados que trazia um teste de associação de palavras. A análise dos dados teve como base a análise de conteúdo proposta por Bardin (2011) e foi feita em três etapas: pré-análise, exploração do material e interpretação. Da exploração dos dados (palavras evocadas e textuais produzidas nos questionários) emergiram quatro dimensões - 10 categorias e 31 subcategorias - das representações dos servidores a respeito da reforma do Judiciário, a saber: reforma gerencial, ampliação da cidadania, aspectos legais e reflexões sobre o Judiciário.

Por fim, são traçadas considerações a respeito da relevância de compreender como os servidores entendem o processo de reforma. Uma compreensão aprofundada pode auxiliar futuros desenvolvimentos de estratégias organizacionais e políticas públicas voltadas para o desenvolvimento dos quadros de servidores do Tribunal de Justiça do Estado da Bahia, assim como servir como referência para outros tribunais.

\section{0 contexto da Reforma do Poder Judiciário}

Como aponta Lustosa da Costa (2010), o processo de reforma do Estado é um processo político, ainda que os reformadores de orientação gerencialista procurem tratar esse processo como técnico, objeto de políticas pragmáticas. Dessa forma, deve ser considerado que a reforma do Judiciário tem sua origem no processo de redemocratização do Brasil. Sadek (2004) enfatiza que a Constituição de 1988 auferiu ao Poder Judiciário ampliação da margem de sua atuação e, em consequência, nova identidade e nova posição na organização tripartite dos poderes, e ampliou seu papel político. A Constituição de 1988 reorganizou a estrutura do Judiciário, redefinindo as atribuições dos organismos que o compõem: foram criados o Superior Tribunal de Justiça (STJ) — que incorporou atribuições anteriormente destinadas ao Superior Tribunal Federal (STF), que passou a tratar de questões constitucionais - e os Juizados Especiais.

Ao colocar o Poder Judiciário no centro da vida pública, a Carta de 1988 trouxe maior importância política a esse poder, mas também o deixou mais à vista da sociedade. Assim, não é surpreendente que o Judiciário brasileiro tenha sido trazido para o mesmo patamar dos demais serviços públicos e tenha se tornado fonte de insatisfação dos cidadãos (Sauerbronn, 2011). Como coloca Frühling (1997), com a ascensão de governos democráticos, passam a existir pressões pela reforma do Judiciário em toda a América Latina. Pressões externas, muitas vezes disfarçadas de apoio por parte de organismos internacionais, governos estrangeiros e corporações multinacionais que necessitam de segurança jurídica para implantar a 
ampliação de seus mercados; e pressões internas, como consequência do fortalecimento das democracias e dos governos constitucionais.

Quando o debate acerca da reforma do Estado retornou ao cenário nacional durante a administração Fernando Henrique Cardoso (FHC), a reforma do Judiciário foi incluída na agenda. A crise de confiança nos governos fez com que os cidadãos estendessem a intolerância à baixa eficiência também da prestação de serviços jurisdicionais. Conforme aponta Sadek (2004), desde o Brasil colônia havia desconforto com a inoperância das Cortes, mas a baixa performance do Judiciário passou a ser associada mais recentemente à sua resistência à mudança, tanto no ponto de vista organizacional (das políticas), quanto administrativo (dos processos).

Assim, quando instituído o Ministério da Administração Federal e da Reforma do Estado (Mare) em 1995, também fazia parte dos planos da administração pública a reestruturação do Judiciário. Entretanto, segundo Bresser-Pereira (1996), o Judiciário rejeitou fortemente a reforma e a implantação de uma cultura gerencial. Dessa forma, durante a administração FHC, a reforma do Estado, no âmbito dos três poderes da União, avançou basicamente no Executivo federal e não foram adiante as reformas política e do Judiciário que eram pretendidas. Ainda assim, haviam sido lançadas as bases para a reforma que seria posteriormente realizada.

Ao entendermos o Poder Judiciário a partir de suas atribuições de poder de Estado e de órgão público prestador de serviços, como propõe Sadek (2004), percebemos que, por mais que a atuação política do Judiciário provoque discussões e controvérsias, é sua atuação como serviço público que se encontrava (e ainda se encontra) realmente em crise e precisava ser resolvida prioritariamente. Depois de mais de uma década de tramitação no Congresso, a reforma do Judiciário foi aprovada em dezembro de 2004. A Emenda Constitucional no 45 tinha como objetivo aumentar a capilaridade do sistema judicial brasileiro, tornando-o mais acessível e ágil e viabilizando a solução institucional de conflitos que, devido ao tempo excessivo e à distância da Justiça, terminavam por ser resolvidos na arena privada (Ribeiro, 2008:469).

Visto que sempre houve resistência por parte dos magistrados à instalação de um órgão de planejamento, coordenação e controle do Judiciário, podemos considerar que a criação do Conselho Nacional de Justiça (CNJ) foi a grande inovação imposta pela Emenda Constitucional no 45. Mesmo tendo sua composição aparentemente mais próxima às questões doutrinárias da aplicação do direito, o CNJ foi aparelhado para tratar das questões administrativas e financeiras dos tribunais. A criação do CNJ trouxe o foco da administração pública para o Judiciário no sentido de se desenvolver maior atenção à área meio dentro dos tribunais. $\mathrm{O}$ CNJ passou a estabelecer metas a serem cumpridas pelos tribunais e a punir os membros do Judiciário que não as cumprissem, em uma atuação impregnada da essência do gerencialismo que caracterizou a reforma do Estado brasileiro. Dessa forma, os magistrados passaram a entender ser necessário dar maior atenção à gestão de suas varas e o CNJ passou a incentivar de forma inequívoca a capacitação de juízes e serventuários, principalmente em disciplinas relacionadas a administração. Mesmo observando grandes resistências, a partir desse momento se iniciou a aproximação dos tribunais à prestação de serviços públicos e esse seria o primeiro passo na direção de se democratizar o acesso à Justiça. 
O funcionamento da Justiça passou a ser enquadrado com base em quatro dimensões: a) duração razoável do processo; b) proporcionalidade entre o número de juízes na unidade jurisdicional, a efetiva demanda judicial e a respectiva população; c) funcionamento ininterrupto da atividade jurisdicional; e d) distribuição imediata dos processos em todos os graus de jurisdição. Assim, nos âmbitos judicial e administrativo, buscou-se assegurar a razoável duração do processo e os meios que garantissem a celeridade de sua tramitação e, além disso, passaram a ser atribuídas responsabilidades aos membros do Judiciário. Como aponta Sauerbronn (2011:99), a reforma do Judiciário demonstrou claramente seu caráter advindo da perspectiva da New Public Management e atacou dois males observados na administração burocrática: ineficiência relacionada ao excesso de procedimentos e controles processuais e baixa responsabilização dos burocratas diante do sistema político e da sociedade.

Desde sua implantação, o CNJ tem planejado e cobrado de juízes e serventuários atuações mais condizentes com as necessidades da população e ações que promovam aumento da transparência da prestação jurisdicional. Segundo Ribeiro (2008:470), a análise das atividades desenvolvidas pelo CNJ parece deixar clara a preocupação deste não apenas com os processos iniciados especialmente por excesso de prazo nos tribunais, mas também em instituir sistemas que permitam um acompanhamento mais próximo e criterioso do que ocorre nos tribunais. Esses sistemas, por sua vez, são indispensáveis para que o CNJ possa desenvolver ações pontuais destinadas a reduzir a morosidade processual, tornar os procedimentos judiciais menos complexos (pela ênfase nos procedimentos alternativos de justiça - como a conciliação) e ainda aumentar a transparência na prestação jurisdicional. Os tribunais em todo o país passaram a desenvolver seus planejamentos com o objetivo de aumentar a transparência e modernizar a gestão do Judiciário de forma a aumentar a satisfação dos cidadãos, que passam a ser enxergados como clientes das entregas de serviços públicos.

O CNJ definiu como urgente a análise da prestação do serviço oferecida pelos tribunais e, dessa forma, o desempenho do Judiciário passou a ser, de alguma forma, avaliado. Essa avaliação expôs a incapacidade do poder em oferecer a prestação de serviços condizentes com as expectativas dos cidadãos e deixou claro o despreparo de magistrados e servidores em lidar com a gestão da prestação jurisdicional. Em que pesem a importância dos magistrados para a oferta de justiça e a projeção social dessa carreira, tanto juízes quanto servidores do Judiciário tiveram suas atividades profundamente impactadas pela reforma do Judiciário.

\section{A Perspectiva da teoria das representações sociais}

A teoria das representações sociais (TRS) foi proposta por Moscovici em 1961 com o objetivo de oferecer uma forma de teorização a respeito da interação entre os níveis individual e coletivo. Segundo Jovchelovitch (1998), a perspectiva desenvolvida por Moscovici parte dos conceitos de representações coletivas, elaborado por Durkheim, e de produção dos saberes sociais a partir de processos inconscientes, de Freud. Dessa forma, conforme exposto por Jodelet 
(2001), a TRS trata da representação de alguém (sujeito) a respeito de alguma coisa (objeto) por meio de relações simbólicas e interpretativas.

Para Jodelet (2001), as representações sociais são modalidades de conhecimento prático orientadas para a comunicação e para a compreensão do contexto social, material e ideativo em que vivemos. Como enfatiza Spink (1993), essas representações são socialmente elaboradas e compartilhadas e servem como base para a construção de uma realidade comum que possibilita a comunicação entre indivíduos. Araújo (2008:100) aponta que as representações sociais "são elaboradas na relação dos indivíduos em seu grupo social, na ação no espaço coletivo comum a todos, sendo assim, diferente da ação individual". Para Moscovici (2004), os indivíduos pensam por meio de uma linguagem e organizam seus pensamentos de acordo com um sistema que está condicionado, tanto por suas representações, quanto pela cultura.

Ainda segundo Moscovici (2004), as representações a respeito das coisas que cercam as pessoas são partilhadas por elas e as influenciam, visto que se impõem como uma combinação de uma estrutura que está presente anteriormente ao processo cognitivo e de uma tradição que define o que deve ser pensado. Desse modo, as representações sociais são fenômenos sociais que, mesmo acessados a partir de seu conteúdo cognitivo, têm de ser entendidos a partir do seu contexto de produção. Ou seja, a partir das funções simbólicas e ideológicas a que servem e das formas de comunicação onde circulam, como aponta Spink (1993). Segundo Reis e Bellini (2011), as representações sociais são os conjuntos de explicações que se originam por meio das comunicações entre indivíduos na vida cotidiana. Essas explicações são possíveis porque o sujeito se dedica ao trabalho mental de formar uma imagem do objeto. Esse esforço aproxima sujeito e objeto e faz com que relações entre o mundo interior do indivíduo e seu universo sociocultural se estabeleçam com o objetivo de incorporar o objeto que está à sua frente. Essa incorporação se dá a partir da significação. Nesse sentido, as representações sociais permitem ao sujeito tomar consciência de seus pensamentos, ideias e atitudes e tornar familiar aquilo que lhe é desconhecido (Reis e Bellini, 2011).

Jodelet (2001) propõe a representação social sempre como a representação de alguma coisa (objeto) e de alguém (sujeito). A representação é uma interpretação, uma valoração, ou uma descrição que é necessária para que os indivíduos sejam capazes de atribuir significado ao objeto. Como apontam Bueno e Freitas (2011:7), o ponto de partida, a matéria-prima para a construção dessas realidades consensuais vem dos universos reificados, por meio das suas representações. A representação social tem com o seu objeto uma relação de simbolização e de interpretação.

A partir de interações (conversações e diálogos) os indivíduos passam a atribuir significados aos objetos que desejam conhecer e com os quais querem se relacionar. Isso não significa, contudo, que as representações sociais tenham um caráter estático. Visto que as trajetórias dos grupos sociais são dinâmicas, há um processo permanente de significação que é baseado nas contínuas ações coletivas dos indivíduos e suas relações restabelecidas dentro e fora do grupo, no encontro com outros indivíduos ou outros grupos sociais (Spink, 1993). Para Reis e Bellini (2011), esse processo incessante faz com que um objeto venha a tornar-se uma realidade social, a partir das representações que os conjuntos de indivíduos fazem dele. 
A TRS se consolidou no âmbito da psicologia social e trouxe um importante aporte teórico aos pesquisadores que buscam compreender os significados e os processos neles imbricados, criados pelos homens para explicar o mundo e sua inserção dentro dele, como afirmam Almeida e Cunha (2003). Segundo Reis e Bellini (2011:149), a TRS é uma teoria sobre a produção dos saberes sociais. Dessa forma, conforme Jovchelovitch (1998), a TRS se dirige aos saberes que se produzem no cotidiano, presentes no mundo vivido pelos indivíduos. Assim, é por meio das relações sociais que emergem as representações, permitindo ao sujeito a descoberta do mundo, bem como sua construção. A representação social funciona como uma forma de interpretação da realidade por parte do sujeito. Como aponta Cavedon (2008), as representações sociais são fruto do meio social, por meio do compartilhamento de significados. As representações não são criadas por indivíduos de maneira isolada, mas são constituídas por pessoas e grupos, ao longo da cooperação e da comunicação.

A TRS é utilizada como forma de compreender a maneira pela qual indivíduos ou grupos sociais percebem, interpretam e expressam os fenômenos sociais no cotidiano. Segundo Lescura e colaboradores (2012), do ponto de vista prático, as técnicas verbais são as mais utilizadas pelos pesquisadores que buscam apreender as representações e, portanto, devem concentrar-se nos processos de comunicação. Uma vez que a comunicação é compreendida como forma de mediação social, ritos, mitos e símbolos tornam-se mediações entre mundo desconhecido e mundo da intersubjetividade humana.

\section{Procedimentos metodológicos}

Tendo em vista o caráter exploratório da pesquisa e a perspectiva da TRS, a opção dos pesquisadores foi adotar uma abordagem qualitativa. Dessa forma, foi definida uma estratégia de pesquisa que possibilitasse aos pesquisadores recolherem as representações de servidores de forma a revelar seus sentidos para a reforma do Judiciário. Essa estratégia de pesquisa levou em consideração a grande quantidade de servidores dispostos a participar e a implicação desse grande número de participantes para o processo de análise dos dados.

O critério utilizado para seleção dos respondentes foi a facilidade de acesso. Os dados foram coletados junto a 263 servidores do Tribunal de Justiça do Estado da Bahia (TJBA) participantes de um curso de capacitação promovido pela Universidade Corporativa do Tribunal de Justiça do Estado da Bahia (Unicorp) na cidade de Salvador no período de março de 2011 a novembro de 2013. O curso tinha como objetivo promover a melhoria na gestão jurisdicional a partir da atualização do conhecimento, do desenvolvimento de competências e do treinamento dos servidores para o uso de ferramentas de gestão. Além disso, o convívio e a discussão entre servidores vindos de comarcas de todo o estado da Bahia trouxeram aproximação entre os servidores e tornaram o ambiente de aprendizado motivador. O programa contou com carga horária de 100 horas/aula, distribuídas em três linhas de ação, divididas por competências: essenciais (que tratava de ética no serviço público, cidadania organizacional e conhecimentos gerais); técnicas (que contemplava temas de direito e legislação); e 
estratégicas e de gestão (que discutia princípios de administração pública, gestão de pessoas e gestão de serviços públicos).

Os entrevistados tinham idades entre 22 e 67 anos (média de 43 anos), eram majoritariamente do sexo feminino (67\% dos respondentes) e tinham entre 1 ano e 38 anos de tempo de serviço no tribunal (média de 14 anos de serviço). No tocante à escolaridade, menos de 1\% dos entrevistados tinha apenas o ensino fundamental concluído; 22,7\% tinham o curso médio completo, 4,6\% tinham curso superior incompleto; 42,3\% tinham curso superior completo; e 29,6\% tinham pós-graduação.

Considerando o objetivo da pesquisa de compreender de forma ampla o que a reforma do Judiciário representa para seus servidores e dada a variabilidade de cargos, escolaridade e tempo de serviço, não foram discriminados cargos ocupados por servidores com formação de nível superior (analistas judiciários) daqueles ocupados por servidores com formação de nível médio (técnicos judiciários e auxiliares judiciários). Como são preenchidos por concurso e não há mobilidade vertical, os cargos de nível médio, por exemplo, contemplam também servidores com nível superior.

A pesquisa foi autorizada pela Unicorp e todo o suporte foi oferecido aos pesquisadores sem que houvesse qualquer interferência na pesquisa. A coleta de dados aconteceu antes da apresentação das disciplinas de administração e gestão pública e serviu como introdução para a discussão sobre esses temas. Antes da distribuição dos questionários foram apresentados os detalhes do instrumento de coleta de dados e foi deixado claro aos servidores que suas respostas não seriam identificadas e que todos os dados brutos seriam acessados somente pela equipe de pesquisa. Foi esclarecido que a pesquisa tinha sido desenvolvida pelo grupo de pesquisa interinstitucional e que, mesmo autorizada e apoiada pela Unicorp e pelo TJBA, tinha caráter eminentemente acadêmico.

A fim de serem levantadas as representações sociais espontaneamente partilhadas pelos membros do grupo de servidores da Justiça, o instrumento de coleta de dados aplicado trazia um teste de associação de palavras. O uso da livre associação de palavras teve como objetivo tornar acessível o repertório conceitual dos respondentes e, dessa forma, tornar possível a unificação dos universos semânticos de palavras comuns diante dos estímulos indutores utilizados no estudo, conforme proposto por Castanha e colaboradores (2007).

$\mathrm{O}$ instrumento de coleta de dados continha duas partes. Na primeira parte encontravam-se perguntas descritivas do perfil do funcionário (idade, sexo, grau de instrução, tempo de serviço no TJ e função atual). Na segunda parte, um texto orientava a ação do respondente e solicitava que fossem listadas três palavras ou expressões que lhe viessem à mente quando ouvia a expressão "Reforma do Judiciário". Para que os respondentes não ultrapassassem a quantidade de palavras ou expressões apresentadas, o espaço para respostas era de três linhas em branco. Em seguida, outro enunciado solicitava ao respondente que apontasse a palavra ou expressão que considerasse mais importante dentre as três listadas anteriormente e escrevesse um texto explicando o significado dessa palavra ou expressão.

A análise dos dados coletados foi feita de acordo com o método de análise de conteúdo. Segundo Bardin (2011), esse método de análise é dividido em três etapas: pré-análise, explo- 
ração do material e interpretação. Durante a pré-análise, com apoio do software de análise de dados ATLAS/ti, os dados foram tabulados e foi feita a categorização das palavras evocadas em torno de eixos temáticos que expressavam o mesmo sentido, conteúdo e carga emocional. Esse primeiro esforço de interpretação dos núcleos organizadores dos discursos, das variáveis e das categorias serviu como uma visão geral do material coletado e permitiu as primeiras reflexões dos pesquisadores.

As categorias foram construídas com base na pertinência, isto é, a adequação dos dados coletados como fontes de informação adequadas para os pesquisadores. Os pesquisadores são ambos economistas, com mestrado em administração pública e doutorado em administração, membros de um grupo de pesquisa interinstitucional sobre administração pública, com experiência como consultores em organizações do setor público.

Durante a exploração, as categorias formadas foram revistas mais atentamente com o objetivo de revelar sentidos e significados e, como consequência, foram definidas dimensões das representações dos servidores. A fase de interpretação trouxe a descrição final de cada dimensão, categoria e subcategoria.

A seção seguinte traz os resultados da análise dos dados, apresentando as dimensões, categorias e os eixos temáticos das representações dos servidores sobre a reforma do Judiciário. Alguns trechos de textos escritos pelos servidores são apresentados ao longo da análise.

\section{Análise dos dados}

Os servidores se mostraram bastante à vontade durante o preenchimento dos instrumentos de coleta de dados e muitos deixaram clara a satisfação diante da possibilidade de expressarem suas posições a respeito da reforma do Judiciário. Ao todo, foram aplicados 263 questionários e, a partir deles, foram levantadas 795 palavras evocadas.

Seguindo a proposta de Bardin (2011), a etapa de pré-análise dos dados possibilitou a organização das palavras evocadas em subcategorias que deram origem aos eixos temáticos e às categorias de palavras de acordo com as interpretações feitas a respeito dos sentidos, conteúdos e cargas emocionais presentes nas palavras. As subcategorias foram construídas fundamentalmente com base em aproximações semânticas capazes de gerar agrupamentos de palavras. Nesse sentido, em função de não haver aproximações semânticas diferenciadas, os eixos cidadania, aspectos legais, infraestrutura e tempo mantiveram-se sem subcategorias.

As palavras componentes das subcategorias foram alinhadas em eixos temáticos com base nas aproximações de sentido e significado, que deram suporte à nomeação de 10 categorias, agrupadas em quatro dimensões com base nos temas que emergiram de cada categoria. O quadro 1 apresenta as subcategorias e suas respectivas quantidades de ocorrência, os eixos temáticos e as categorias construídas a partir da análise de conteúdo realizada. Essa análise permitiu a proposição de quatro dimensões das representações sociais da reforma do Judiciário pelos servidores do TJBA. 
Quadro 1

Descrição de subcategorias, eixos temáticos, categorias e dimensões

\begin{tabular}{|c|c|c|c|}
\hline Subcategorias (ocorrências) & Eixo temático & Categoria & Dimensão \\
\hline $\begin{array}{c}\text { celeridade (95); qualidade (68); critérios } \\
\text { de gestão (29); atendimento (28); } \\
\text { funções gerenciais (22); informatização e } \\
\text { tecnologia (22); meta (10); redução da } \\
\text { burocracia (9) }\end{array}$ & $\begin{array}{c}\text { palavras associadas, } \\
\text { fundamentalmente, à atividade } \\
\text { meio e à gestão dos processos } \\
\text { jurisdicionais }\end{array}$ & Gestão de Processos & \multirow{5}{*}{ Reforma Gerencial } \\
\hline $\begin{array}{l}\text { valores de justiça (60); transparência } \\
\text { (28); moralidade e confiabilidade (20); } \\
\text { igualdade (12); valores individuais (9) }\end{array}$ & $\begin{array}{l}\text { palavras associadas aos } \\
\text { valores que devem orientar o } \\
\text { Judiciário e serem praticados por } \\
\text { servidores e magistrados }\end{array}$ & $\begin{array}{c}\text { Valores } \\
\text { Organizacionais }\end{array}$ & \\
\hline $\begin{array}{l}\text { treinamento e desenvolvimento } \\
\text { (42); valorização (39); salário (22); } \\
\text { reestruturação do quadro (1 1); } \\
\text { comunicação e liderança (6) }\end{array}$ & $\begin{array}{c}\text { palavras associadas à } \\
\text { preocupação com a gestão de } \\
\text { pessoas, suas práticas e políticas }\end{array}$ & Gestão de Pessoas & \\
\hline $\begin{array}{l}\text { melhorias necessárias no relacionamento } \\
\qquad \begin{array}{c}\text { (41); aspectos negativos do } \\
\text { relacionamento (4) }\end{array}\end{array}$ & $\begin{array}{l}\text { palavras associadas às } \\
\text { preocupação dos respondentes } \\
\text { com os relacionamentos entre } \\
\text { pessoas no tribunal }\end{array}$ & Relações Interpessoais & \\
\hline infraestrutura (28 - sem subcategorias) & $\begin{array}{c}\text { palavras associadas à } \\
\text { infraestrutura necessária para } \\
\text { que a reforma tenha condições } \\
\text { para acontecer }\end{array}$ & infraestrutura & \\
\hline cidadania (46 - sem subcategorias) & $\begin{array}{l}\text { palavras cujo foco se direcionava } \\
\text { para a entrega do serviço } \\
\text { ao cidadão e ao retorno à } \\
\text { sociedade }\end{array}$ & Cidadania & $\begin{array}{l}\text { Ampliação da } \\
\text { Cidadania }\end{array}$ \\
\hline $\begin{array}{c}\text { pequena mudança (16); grande mudança } \\
\text { (58) }\end{array}$ & $\begin{array}{l}\text { palavras associadas à promoção } \\
\text { de mudança }\end{array}$ & Mudança & \multirow{3}{*}{$\begin{array}{c}\text { Reflexões sobre o } \\
\text { Judiciário }\end{array}$} \\
\hline $\begin{array}{l}\text { de necessidade da reforma (13); } \\
\text { de dificuldade da reforma (9); de } \\
\text { idealização (3); sentimentos positivos (3); } \\
\text { sentimentos negativos (2) }\end{array}$ & $\begin{array}{l}\text { palavras relacionadas aos } \\
\text { sentimentos das pessoas em } \\
\text { relação à reforma, que podem } \\
\text { ser positivos ou negativos }\end{array}$ & Sentimentos & \\
\hline tempo (13 - sem subcategorias) & $\begin{array}{c}\text { palavras relacionadas à } \\
\text { dimensão temporal da reforma e } \\
\text { sua premência }\end{array}$ & Tempo & \\
\hline aspectos legais (27 - sem subcategorias) & $\begin{array}{l}\text { palavras relacionadas às leis } \\
\text { e aos códigos, ou seja, aos } \\
\text { aspectos jurídicos e não } \\
\text { gerenciais }\end{array}$ & Aspectos Legais & Legislação \\
\hline
\end{tabular}

Fonte: Elaborado pelos autores. 
A organização das palavras em torno dos eixos temáticos revelou as associações centrais com a reforma do Judiciário manifestadas pelos servidores de forma bastante clara. Seguindo a proposta metodológica da TRS, a contagem de palavras evocadas permitiu a compreensão a respeito das categorias que informam os elementos centrais e periféricos que constituem a representação, segundo a perspectiva dos respondentes. A contagem de palavras, contudo, não significa a perda do caráter qualitativo da proposta da TRS, mas serve como informação adicional ao processo de interpretação das representações sociais. A figura 1 mostra a distribuição de evocações por eixo temático, que, como sugerido por Bardin (2011), permite a representação da informação de forma condensada.

Figura 1

Distribuição das evocações por eixo temático

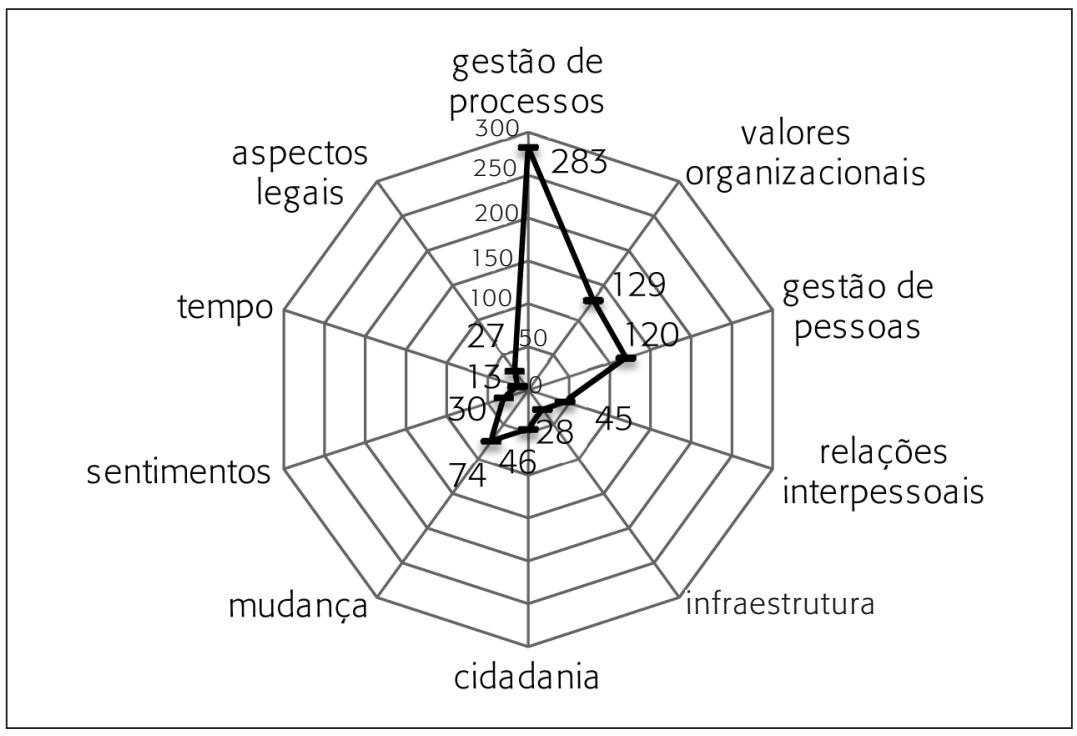

Fonte: Elaborados pelos autores.

Nesse sentido, em linha com os elementos preconizados na literatura, mostrou-se preponderante a dimensão de gestão de processos com 283 palavras evocadas. O trecho a seguir, reproduzido de um dos questionários aplicados, mostra-se representativo do sentido empregado pelos servidores e demarca claramente a separação entre os aspectos legais e os aspectos de gestão: "No aspecto prático, a reforma não deverá ser aplicada apenas no âmbito legal, com relação à legislação e ordenamento jurídico, mas também é tão importante a questão de gestão e todos os aspectos organizacionais, estruturais etc."

Para os servidores do TJBA a reforma assume principalmente o significado de reforma gerencial, o que pode ser mais explorado nas categorias Gestão de Processos, gestão de pessoas, relações interpessoais, infraestrutura e até mesmo na proposição de valores organizacionais. As 
subcategorias relacionadas a essas categorias deixam clara a amplitude da dimensão gerencial da reforma e as diversas possibilidades de abordá-la.

Dentre as subcategorias de gestão de processos, destacam-se celeridade e agilidade como significados evocados mais frequentemente pelos respondentes. Celeridade foi a mais citada pelos servidores, tendo sido evocadas 95 vezes as palavras associadas. Isso pode ser explicado como reflexo das ações do CNJ objetivando a "duração razoável do processo". As metas impostas pelo órgão, por meio de seus indicadores oriundos do Balanced Scorecard, em grande parte, elegem o tempo como principal recurso a ser observado e a eficiência dos tribunais é medida com base na quantidade de processos julgados a cada ano, em cada instância. Em suas respostas, os servidores relacionaram celeridade, de forma bastante objetiva, a "menor tempo para dar um resultado aos interessados", "rapidez na prestação de qualquer serviço", e associaram celeridade também à "necessidade de uma justiça mais rápida com solução de conflitos em tempo satisfatório".

Para os servidores, a celeridade no Judiciário está associada aos processos de trabalho, como explicado pelos servidores em suas respostas:

No judiciário, a celeridade processual representa para todo o cidadão um resultado mais rápido e eficaz para solucionar os conflitos e para pôr fim nas demandas que afligem a sociedade como um todo. Só assim pode o judiciário transformar a sua imagem como um órgão transparente capaz de solucionar os conflitos sociais de maneira justa, buscando o bem comum.

A representação dos servidores da reforma como celeridade apareceu relacionada à gestão do processo de prestação de serviços jurisdicionais, que também apareceu relacionada a qualidade, eficiência, eficácia e economicidade, além da busca de excelência da prestação de serviços:

Na medida em que uma justiça tardia não é justa e que o sistema, tal como está é lentíssimo, é preciso reformular o atual judiciário em busca da celeridade e da efetividade sem, no entanto, perder de vista a qualidade.

Prestar um serviço de qualidade para sociedade se faz urgente nos dias de hoje. Acredito que a reforma do judiciário poderia ajudar no aprimoramento da qualidade e dos processos, atendendo de forma eficiente e dando um grande passo em direção a excelência.

A eficiência seria a mais importante, pois levaria a uma melhor prestação jurisdicional. (...) Poderia se afirmar também que uma gestão eficiente levaria à reforma do judiciário.

Ainda nesse eixo temático, a reforma assume também o sentido de: (a) busca pelo pleno desenvolvimento das funções gerenciais relacionadas à melhoria dos trâmites processuais, como planejamento, organização e controle, totalizando 22 evocações; (b) incorporação da tecnologia da informação aos trâmites processuais por meio de novos sistemas e digitaliza- 
ção/virtualização dos processos, também com 22 evocações; (c) preocupações com critérios de gestão como eficiência, eficácia e economicidade nas atividades jurisdicionais, com 19 palavras evocadas; e (d) o fim da burocracia por meio de redução do formalismo, simplificação e desburocratização, com 9 palavras.

Gestão é a palavra mais importante, porque entendo que seja a mais abrangente, que nos dá um significado de gestão de coisa pública, gestão de pessoal, gestão de trabalho, gestão de recursos.

A segunda categoria mais frequente na construção da representação social da reforma apresenta os valores organizacionais do Judiciário a serem considerados no âmbito da reforma (129 no total). O eixo temático dessa categoria está baseado em palavras associadas aos valores que devem orientar o Judiciário e serem praticados por servidores e magistrados em suas atividades cotidianas. Destacam-se nessa categoria as palavras justiça (27 evocações), transparência (24), ética (18).

O judiciário precisa ser reformado para atender aos anseios de justiça da sociedade que o legitima. Infelizmente ou não, é o judiciário quem pode minimizar ou afastar as falhas dos demais setores da sociedade: públicos ou privados.

Através de transparência diante da sociedade, mídia e outros meios que tenham acesso direto ou indireto com o tribunal e sua prestação jurisdicional veem de ponto que ele está em pleno movimento, e este movimento é continuo, modernizado, mais humano, mais estruturado, seja físico, seja no comportamento de seus servidores.

Surge também nesse eixo o significado da reforma associado a oportunidade de moralização, confiabilidade e adequada utilização de recursos financeiros (20 evocações), credibilidade (10) e igualdade (12).

Acredito que com a moralização da justiça, do poder judiciário, serão aplicados os recursos de forma correta (...) A corrupção é uma doença que seria exterminada com a moralização do poder judiciário.

Confiar é primordial para o cidadão, e por isso o judiciário precisa transformar o descrédito em confiança junto ao povo (...) A princípio é preciso resgatar a credibilidade não só do corpo de servidores, como também da sociedade em geral.

Dar a todos e a cada um dos clientes internos e externos aquilo que é direito e cabível dentro dos padrões de reciprocidade a serem estabelecidos.

Essa categoria mostra a expectativa dos servidores com relação à refundação da organização judiciária, baseada na possibilidade de se tornar uma organização mais bem gerida, 
acessível e focada na entrega efetiva de solução de conflitos. Essa ideia de reorientação dos valores da organização também é muito influenciada pelas ações do CNJ. Desde sua implantação, o CNJ tem exigido de todos os tribunais brasileiros a construção de um planejamento estratégico que é revisto a cada três anos. A metodologia de elaboração do planejamento estratégico desenvolvida pelo CNJ se inicia com a definição da visão estratégica e dos valores que orientam a organização. Mesmo sem terem participação efetiva na elaboração dos documentos de planejamento do TJBA, os servidores passaram a ter um documento ao qual se referenciar para entenderem seus papéis no tribunal.

Em grande medida, tanto a prática de valores de justiça quanto a gestão de processos explicam a emergência dos eixos temáticos gestão de pessoas e relacionamento interpessoal por serem estes frequentemente relacionados nos textos apresentados pelos respondentes. Destacam-se na gestão de pessoas as subcategorias treinamento e desenvolvimento (42) e comunicação e liderança (6).

A prática da qualificação fará com que as pessoas possam ter acesso ao judiciário com mais fé no resultado ainda mais rápido e com muito mais qualidade.

Através do treinamento temos a padronização dos processos, melhoria no atendimento, celeridade nos serviços e reconhecimento do servidor.

Assumem também um caráter central as subcategorias valorização (39), salário (22), reestruturação do quadro de servidores (11), que, em associação, atribuem relevância às políticas de gestão de pessoas no processo de reforma no TJBA.

É preciso isonomia salarial, partindo do pressuposto de que a motivação, o incentivo e o respeito com o servidor são elementos fundamentais. (...) Oferecer condiç̃os materiais financeiras (salários) para que tenhamos sustentabilidade na escolha que fizemos.

No momento para mim, condição favorável de trabalho é primordial. A questão de falta de pessoal, por exemplo, é gritante, visível e urgente em todos os cartórios.

Os gestores devem olhar mais para o seu funcionário com carinho (...) quem desenvolve as atividades precisa estar motivado, feliz com o ambiente, tendo um bom relacionamento, para que o serviço desenvolvido seja aperfeiçoado a cada dia. Sem esta motivação será difícil planejar a reforma do judiciário e alcançá-la.

As palavras evocadas indicam que os servidores da justiça possuem uma percepção de que são vistos como pertencendo a uma categoria de trabalhadores desprestigiada e desvalorizada e cujas atividades são normalmente entendidas como secundárias à atuação dos magistrados. Segundo os textos, há uma divisão clara dentro dos tribunais e a reforma traz a possibilidade de reconhecimento profissional dos servidores. Está claro mais uma vez a pre- 
sença de um discurso gerencial, relacionado à meritocracia e não à distinção de classes dentro da administração pública.

Os significados da reforma associados às políticas de valorização e incentivo, conforme relatos apresentados, tornam-se ainda mais relevantes ao levarmos em consideração a categoria relacionamentos interpessoais (45), dentre os quais se encontram relatos sobre aspectos negativos (4) — "a reforma deve ser o fim da arrogância e da prepotência" — e destacam-se melhorias consideradas necessárias nos relacionamentos, por meio da evocação de diversas palavras como respeito, humanização, ver o outro, melhor relação, humildade, entrosamento, novas posturas.

A valorização do servidor pelo poder judiciário começa com humanização, reconhecimento, motivação. O servidor precisa ser tratado como pessoa humana e não só como empregado do estado, ser reconhecido é tão importante quanto o seu salário.

É preciso que haja empenho dos magistrados em conjunto com os servidores, haja vista, que a mentalidade dos que ingressam hoje no judiciário é diferente daquela de 50 anos trás.

As dimensões associadas às pessoas e aos relacionamentos nos remetem a outros recursos necessários à prática jurisdicional e que foram evocados pelos respondentes. Destacam-se, nesse sentido, palavras relacionadas à infraestrutura (28), recursos materiais e condições de trabalho, como nos textos: "A reforma do judiciário passa por buscar os recursos possíveis para isso, seja de investimento nos recursos humanos ou em equipamentos"; e "Oferecer condições de trabalho, espaço físico e instalações adequadas para que as tarefas sejam executadas da melhor forma possível".

A representação construída pelos servidores, seja a partir da celeridade, dos valores organizacionais, das pessoas ou da infraestrutura, acaba por desaguar na dimensão da cidadania (46 evocações - sem subcategorias). Esse eixo temático agrupa as palavras que direcionam o foco da reforma para a entrega do serviço ao cidadão e retorno à sociedade: "trabalhamos para o cidadão e não devemos esquecer que somos cidadãos. É a origem da sociedade, dos seus interesses". Alguns dos textos anteriormente apresentados revelam esse foco, entretanto, destacam-se adicionalmente aqueles relacionados ao acesso à justiça, de aproximação e retorno à sociedade e prestação de contas:

O acesso à justiça ainda é muito restrito. O cidadão ainda não tem o pleno conhecimento dos seus direitos e deveres, sem falar que em muitos casos é necessário representação para ter o seu direito de ação atendido.

O judiciário tem que deixar de ser só impositivo e procurar saber, aquilo que a população quer (...) o cidadão busca a justiça querendo algo e acaba tendo que seguir aquilo que tem que ser ponto. 
O desejo de construção de uma justiça cidadã reflete a possibilidade de reflexão a respeito do Judiciário e de suas relações com a sociedade, que, se não é praticada pelos magistrados, parece muito importante para os servidores. Essa reflexão leva os servidores a analisarem o Judiciário em uma perspectiva mais ampla. A representação da reforma segundo a visão dos servidores pode ser também analisada a partir da categoria mudança (74), que agrupa palavras que associam a reforma com um verbo de ação relacionado à mudança. Mais especificamente, é possível identificar a associação a grandes transformações (58) — como quebrar paradigmas, transformar, inovar, modernizar - e a verbos que indicam pequenas mudanças (16) - como corrigir, atualizar, renovar, aperfeiçoar, consertar. As diferenças mostram-se nítidas por meio dos seguintes textos:

Inovar no sentido de retirar os velhos moldes do judiciário, com foco direto na sociedade que o legitima, trazendo com ele mais confiança e credibilidade.

Consertar é tornar algo que se encontra velho, fora do padrão atual, sem vida, inoperante e acabado em um objeto, coisa ou instrumento em um estado adequado, novo atual e/ou eficiente.

Ainda no tocante a essa dimensão de reflexão a respeito do Judiciário, houve respondentes que destacaram seus sentimentos em relação à reforma do Judiciário, evocando palavras que remetiam à necessidade da reforma (12), à dificuldade da reforma (10), à idealização (3), positivos (3) e negativos (2): "Há uma necessidade, é fundamental, imprescindível que haja uma reforma no judiciário"; "A reforma do judiciário é necessária e urgente, mas é primordial ser bem feita"; "É a esperança de que pode melhorar. É olhando como construir um poder melhor".

Por fim, a categoria tempo (13 evocações - sem subcategorias) concentra as palavras que destacam a dimensão temporal da reforma, como sua urgência e velocidade de implantação: "Ela tem o significado da pressa da sociedade como um todo em resolver problemas estruturais e de gestão dessa instituição"; "A reforma do judiciário é urgente e extremamente necessária para que o estado possa atender aos interesses da sociedade".

Por estarmos tratando da reforma do Judiciário, era esperado que alguma questão relacionada aos aspectos legais e jurídicos da mesma fosse tratada pelos servidores. Foram evocadas 27 palavras (sem subcategorias) que remetiam às leis, ou seja, aos aspectos jurídicos e não de gestão e constituíram a categoria aspectos legais. A discussão acerca da reforma dos códigos foi lembrada:

A reforma requer, por sua vez, reformas nos nossos códigos, especialmente no CPC e CPP, onde as leis são bem mais velhas e dentro desta perspectiva, a redução de recursos os propriamente ditos da lei, porque estes também ajudam a aumentar, a inchar a máquina do judiciário, assim como as mudanças nos procedimentos legais.

A pouca incidência de representações da reforma do Judiciário baseadas em aspectos jurídico-legais reforça a influência do gerencialismo na administração do Judiciário. As repre- 
sentações dos servidores sobre a reforma do Judiciário compartilham mais de perspectivas da gestão do que do universo jurídico.

\section{Considerações finais}

Neste trabalho é apresentada uma investigação acerca das representações sociais da reforma do Judiciário por parte de servidores do TJBA. Como resultado, são trazidas à tona algumas questões relevantes para o campo da administração pública que se somam aos esforços de outros pesquisadores interessados na gestão do Poder Judiciário. O interesse por esse tema tem crescido no campo mais recentemente.

Partindo da proposta da TRS, a presente pesquisa apresenta quatro dimensões das representações sociais dos servidores a respeito da reforma do Judiciário, que emergiram dos dados, a saber: reforma gerencial; ampliação da cidadania; reflexões sobre o Judiciário; e legislação. Ficou claro que as representações sociais dos servidores do Judiciário sobre a reforma do poder estão associadas de forma bastante profunda à perspectiva gerencial.

A explicação para isso se deve à própria orientação da reforma, desenvolvida na esteira da reforma do Estado de 1995 e marcada pela criação do CNJ, órgão gestor do Judiciário. O CNJ colocou em pauta discussões a respeito da prestação jurisdicional e do planejamento estratégico dos tribunais em um poder eminentemente conservador e avesso a mudanças (Sadek e Arantes, 1994; Bresser-Pereira, 1996).

Portanto, a linguagem da reforma para os servidores é a linguagem da reforma gerencial do Estado, conforme ficou claro nessa pesquisa. O CNJ é a principal fonte de compreensão e entendimento dos servidores a respeito do processo de reforma e suas possibilidades. Mesmo manifestando descontentamento com o aumento da cobrança por desempenho por parte do CNJ, os servidores alinharam suas expectativas às expectativas do órgão, ao contrário dos magistrados (Sadek e Arantes, 1994).

Do ponto de vista das considerações a respeito das estratégias organizacionais, essa pesquisa aponta a importância do desenvolvimento de políticas internas de valorização dos servidores e do incremento das ações de capacitação, treinamento e desenvolvimento dos servidores. Além disso, destaca-se a necessidade da ampliação de ações de participação e democratização do acesso e da gestão do Judiciário, que incluem a incorporação de valores organizacionais adicionais ao planejamento estratégico que conte com a participação dos servidores.

A partir da análise das evocações, depreende-se que as políticas públicas orientadas para a reforma dos tribunais também devem levar em conta a participação dos servidores em suas fases de discussão, implantação e avaliação. Em que pese a dificuldade de separar os papéis de poder de Estado e organização pública prestadora de serviços, parece urgente o aumento do envolvimento da área meio para o desenvolvimento das políticas públicas que tragam resultados efetivos.

Ao fim, não se pode deixar de salientar que a reforma do Judiciário tem sido entendida ou apresentada na literatura como uma questão técnica, centrada no aumento da 
eficiência do Poder Judiciário e no aumento da "segurança jurídica". No entanto, conforme já apontado por Nogueira (2003) e Lustosa da Costa (2010), o processo de reforma é uma questão política.

Dessa forma, passa a ser importante que sejam analisados os diversos pontos que envolvem esse processo e o configuram. Novos estudos devem ser incentivados, principalmente aqueles que incorporem maior proximidade às atividades dos servidores do Judiciário.

\section{Referências}

ALMEIDA, Angela M. O.; CUNHA, Gleicimar G. Representações sociais do desenvolvimento humano. Psicologia: Reflexão e Crítica, v. 15, n. 1, p. 147-155, 2003.

ARAÚJO, Marivânia C. A teoria das representações sociais e a pesquisa antropológica. Revista Hospitalidade, v. 5, n. 2, p. 98-119, 2008.

BARDIN, Laurence. Análise de conteúdo. São Paulo: Edições 70, 2011.

BRESSER-PEREIRA, Luis Carlos. Da administração pública burocrática à gerencial. Revista do Setor Público, v. 47, n. 1, p. 7-40, 1996.

BUENO, Janaína M.; FREITAS, Maria E. Representações sociais e gestão intercultural nas organizações. In: ENANPAD, 35., 2011, Rio de Janeiro. Anais... Rio de Janeiro: Anpad, 2011. p. 11-17.

CASTANHA, Alessandra R. et al. Avaliação da qualidade de vida em soropositivos para o HIV. Estudos de Psicologia, v. 24, n. 1, p. 23-31, 2007.

CAVEDON, Neusa R. Antropologia para administradores. 2. ed. Porto Alegre: UFRGS, 2008.

FRÜHLING, Hugo E. Reforma judiciária e democratização na América Latina. Revista do Serviço Público, v. 48, n. 1, p. 90-125, 1997.

GOMES, Adalmir O.; GUIMARÃES, Tomás A. Desempenho no Judiciário. Conceituação, estado da arte e agenda de pesquisa. Rev. Adm. Pública, v. 47, n. 2, p. 379-401, 2013.

JODELET, Denise. Representações sociais: um domínio em expansão. In: JODELET, Denise (Org.). Representações sociais. Rio de Janeiro: Eduerj, 2001.

JOVCHELOVITCH, Sandra. Representações sociais: para uma fenomenologia dos saberes sociais. Psicologia e Sociedade, v. 10, n. 1, p. 54-68, 1998.

LESCURA, Carolina et al. Representações sociais sobre as relações de parentesco: estudo de caso de um grupo empresarial familiar. Revista de Administração Contemporânea, v. 16, n. 1, p. 98-117, 2012.

LUSTOSA DA COSTA, Frederico. Contribuição para um projeto de reforma democrática do Estado. Rev. Adm. Pública, v. 44, n. 2, p. 239-270, 2010.

MOSCOVICI, Serge. Representações sociais: investigações em psicologia social. 2. ed. Petrópolis: Vozes, 2004. 
NOGUEIRA, José M. M. A gestão do Poder Judiciário nos estudos de administração pública no Brasil: um levantamento da literatura especializada. In: ENAPG, 4., 2010, Vitória. Anais... Vitória: Anpad, 2010. p. 1-17.

NOGUEIRA, José M. M. et al. Estudo exploratório da eficiência dos Tribunais de Justiça estaduais brasileiros usando a Análise Envoltória de Dados (DEA). Rev. Adm. Pública, v. 46, n. 5, p. 13171340, 2012.

NOGUEIRA, Marco A. Sociedade civil, entre político-estatal e o universo gerencial. Revista Brasileira de Ciências Sociais, v. 18, n. 52, p. 185-202, 2003.

REIS, Sebastiana L. A.; BELLINI, Marta. Representações sociais: teoria, procedimentos metodológicos e educação ambiental. Acta Scientarum. Human and Social Sciences, v. 33, n. 2, p. 149-159, 2011.

RIBEIRO, Ludmila. A Emenda Constitucional 45 e a questão do acesso à Justiça. Revista Direito GV, v. 4, n. 2, p. 465-492, 2008.

SADEK, Maria T. Judiciário: mudanças e reformas. Estudos Avançados, v. 18, n. 51, p. 79-101, 2004.

SADEK, Maria T.; ARANTES, Rogério B. A crise do Judiciário e a visão dos juízes. Revista USP, n. 21, p. 34-45, 1994.

SAUERBRONN, João Felipe R. Algumas considerações a respeito da reforma da gestão do Poder Judiciário e a segurança pública. In: LEAL, Ana Beatriz; MUNTEAL FILHO, Oswaldo; ZAMPA, Viviane (Org.). Perspectivas da administração em segurança pública no Brasil. Curitiba: CRV, 2011. p. 91-106.

SAUERBRONN, João Felipe R.; LODI, Marluce D. F. Construção da imagem institucional do Poder Judiciário - uma análise baseada nas campanhas publicitárias do Conselho Nacional de Justiça. Cadernos EBAPE.BR, v. 10, n. 4, p. 925-945, 2012.

SENA, Gabriel A.; SILVA, Edson A.; LUQUINI, Roberto A. A reforma do Poder Judiciário no Brasil: uma análise a partir do modelo gerencial. Revista de Ciências da Administração, v. 14, n. 33, p. 6878, 2012.

SPINK, Mary J. P. O conceito de representação social na abordagem psicossocial. Cadernos de Saúde Pública, v. 9, n. 3, p. 300-308, 1993.

Fernanda Filgueiras Sauerbronn é doutora em administração e professora adjunta do PPGCC da Universidade Federal do Rio de Janeiro (UFRJ). E-mail: fernanda.sauerbronn@facc.ufrj.br.

João Felipe Rammelt Sauerbronn é doutor em administração e professor adjunto do PPGA da Universidade do Grande Rio (Unigranrio). E-mail: joao.sauerbronn@unigranrio.br. 